\title{
You, Hope, Her \& Me: Liminoid invitations and liminoid acts
}

\author{
Dr Joanna Bucknall, University of Portsmouth
}

\begin{abstract}
The purpose of this article is to begin to explicate the nature of micro-performance dramaturgies and the ontology of the agency that this generates for the participants, through a consideration of KeepHouse Performance's PAR heritage and legacy performance You, Hope, Her \& Me, a partnership with the New Theatre Royal in Portsmouth. This article presents a localized understanding of the one-on-one style micro performance strategies through an empirically responsible cognitive materialism ${ }^{1}$ lens, employing notions of the liminal and liminoid to conceptualize the nature of the material and conceptual performance space. An argument is presented for participative dramaturgy to be understood as a liminoid invitation that produces the conditions for participants to engage in liminoid acts. As well as considering the nature of the agency of the micro-encounters, this article also seeks to consider the nature of the documentation practices embedded within those liminoid acts.
\end{abstract}

\section{Key words}

Liminal space, liminoid space, liminoid acts, hybrid, schema, cognitive materialism, creatorly, participant, dramaturgy, documentation, PAR, heritage, legacy, microperformance.

\section{You, Hope, Her \& Me: Liminoid invitations and liminoid acts}

Over the course of this article, I want to explicate the nature of the dramaturgical devices employed in micro-performance, considering the production, reception and documentation of the KeepHouse Performance production: You, Hope, Her \& Me. I will be suggesting that such dramaturgical approaches to micro-performance, present their audience or more aptly their participants with a liminoid invitation, which generates the opportunity by and through performance to create liminoid acts. I will assert that the dramaturgy of a liminoid invitation is a hybrid task-driven approach to performance that employs cultural and performative, conceptual and material architectures in order to generate the opportunity to forge new primary experiences for the participants. I will further suggest that the liminoid invitation of such dramaturgy presents participants with the space in which to create liminoid acts in their role as 'creatorly material participants'. You, Hope, Her \& Me, is a yearlong

\footnotetext{
${ }^{1}$ Cognitive materialism can be understood to carry on in the tradition of phenomenology but with the insights of the more recent and empirical findings of cognitive science; and in this sense can be understood as the application of an empirically informed phenomenology, specific to the creative arts and performance criticism. McConachie and Hart (2006) suggest that our interest in cognition turns to the material bodies of performance, both performer and audience and thus in the arts the project of cognitive science can be defined as cognitive materialism.
} 
micro-performance that seeks to document and perform the localized and specific heritage of the New Theatre Royal in Portsmouth, as it undergoes major development into a learning and teaching theatre. Because of this dimension to the practice concerned, I will also be considering the nature of the documentation practices that have been employed as part of the liminoid invitation of the live microencounter and suggesting ways in which they operate as a performative reenactment of the live event itself but also of the heritage of the specific site. Before I begin to explicate the nature of the production and reception of this microperformance event, I would like to spend a brief time outlining the nature of the project in order to contextualise the following analysis.

KeepHouse Performance, a PAR performance company, was founded in February 2011 by Dr Karen Savage and myself. KeepHouse Performance explores contemporary issues through interdisciplinary approaches. We record and document our processes in innovative and interactive ways. In February of this year (2013), KeepHouse began a yearlong project in collaboration with the New Theatre Royal (NTR) in Portsmouth, as part of the Make Your Mark rebuild project. You, Hope, Her $\&$ Me seeks to document and map the community's 'hopes' for the future of the theatre in light of its redevelopment with the University of Portsmouth, through a series of one-on-one and micro encounters. Karen and myself from KeepHouse Performance participated in this project through a collection of intimate, 15-minute, live, one-on-one-style encounters. The participants were invited to join us for tea. They could either come alone or with a friend. The live encounters were documented and mapped through digital media to produce further performances. Heritage artefacts will continue to perform the participants' 'hopes' for the duration of a year after the first encounter. The documentation of all aspects of the project will eventually be crafted into a quilted artefact - a material mapping of the 'hopes' of the theatre's community - that will be donated back to the NTR for display in the refurbished building. The one-on-one style micro-performance encounters themselves were designed as a performative way in which to gather, reflect and document the theatre community's 'hopes' for the future of the NTR. This project has resonance with Suzanne Lacy's 1987 project entitled: The Crystal Quilt, where 430 women over the age of 60 gathered at a live performance event to share their views on getting older. Keep House's heritage project seeks to document the performance of a group of peoples 'hopes' for the future in a similar manner to Lacy's project. Lacy suggests that, 'The Crystal Quilt now exists in the form of a video, documentary, quilt, photographs and sound piece, combining the original elements of performance, activism and broadcast in an ambitious work that fuses social responsibility with the power of aesthetics', (Tate 2013). You, Hope, Her \& $M e$, will operate in a similar manner, employing the documentation of the live oneon-one experiences of the audience to be continually performed in a variety of artefacts that generate a re-enactment of the performances of the individual participant's liminoid acts.

The dramaturgy of those encounters developed out of the following research question: how can we document, map, record, reflect and perform the community's hopes for the future of the NTR? In order to explore this question, the encounters were structured by a series of social rituals, performative tasks and rules, some of which were explicit to the participants and some of which were implicit to the 
architecture of the event. The task-based nature of the encounters' dramaturgy was constituted by blending together and exploring two different concepts: domestic Western social rituals of the sharing of tea and cake and the more contemporary phenomenon of sharing via social network sites and applications to perform community, legacy and heritage. I want to argue that it is these two aspects of the dramaturgy that are fundamental to generating the conditions for a liminoid invitation. Before I go on to unpack the ontology of those performative devices, I first want to explore the notions of liminal and liminoid, specifically my usage of it as a critical structure for understanding the nature of conceptual and material performance space.

\section{Liminality}

The dramaturgy for this micro-performance relies on the construction of liminal space in order to make liminoid invitations. The liminal is a concept that has been adopted from the discipline of anthropology and adapted as a term most notably by Susan Broadhurst to articulate the radicalized potential of space within performance. Broadhurst suggests that it has grown out of slippages and hybrid forms of performance practice manifest on the edges and in betweens of performance.. She describes the liminal as 'hybrid performances' that 'share certain aesthetic features, such as innovation, interdeterminancy, marginality and an emphasis on the intersemiotic' (Broadhurst 1999: 1). Broadhurst's usage of the term is specifically constructed out of a reading of Victor Turner's study of the liminal (Turner 1969) as a 'marginalized space which holds the possibility of potential forms, structures, conjectures and desires' (Broadhurst 1999: 12). Turner suggests that '[l]iminality is a temporal interface whose properties partially invert those of the already consolidated order which constitutes any specific cultural "cosmos"' (Turner 1982: 41). Broadhurst asserts that the liminal is the space in between and describes forms of performance that push at the edges of what is possible. The potential of this space is therefore what she means when she discusses it in terms of radical or charged space. Baz Kershaw suggests that the polarising notion of radical that arises out of oppositional politics is problematized in the contemporary climate, he argues that with the scepticism towards 'grand' narratives and incredulity towards political process that the oppositional politics of the 1960's are thrown into relief:

The old binary oppositions between, for example, propaganda and art, or politics and aesthetics, or real and imaginary are deeply problematised. In a parallel vein the idea of the 'political' has been applied to a widening range of phenomena: now we have the politics of representation, the politics of the body, identity politics, sexual politics, cultural politics.

(Kershaw 1999: 63)

When the discourses that support those practices are considered within the context of the horrors and failures of the Twentieth Century they are rendered impotent as political gestures and processes. With the collapse of cultural hierarchies it suggests that it is no longer feasible or credible for politics to remain a separate discourse, distinct from other social, cultural and even personal discourse. Radical within this context draws attention to the politics of the personal, a localised axis of constructed discourse and instead represents an experiential possibility. Abrahams suggests that 
by placing emphasis on experience, you underscore expressions as a unit of action. It is these actions that have the potential for social change and social reflection because of the dialectical nature of the model. Abrahams writes that:

Experience underscores the ongoing-ness of life and the open character of ongoing actions, yet it also encourages us to see actions as units of behaviour that can be separated from the rest of the action and talked about later. It is a term of connections because it encourages us to discuss life in terms of how present activities of even the most threatening sort may be drawn on and replayed in some form in the future: 'experience is the best teacher', 'live and learn', and all that.

(Abrahams in Turner and Bruner 1986: 49)

Abrahams suggests that to realise ourselves as individuals and draw meaning from expression and ensuing action, we are reliant upon our context and the experience of others for meaning and validation. That, in seeking our identity as individuals we search for 'typicality'. Broadhurst's hybridised liminal space can be understood as radical because it de-doxifies the very nature of action through the performative lens that it generates.

The liminal then, in terms of one-on-one micro performance dramaturgy, can be understood as practices that sit at the edge of possibilities and between the boundaries of forms and disciplines. It would appear that because of the space that the liminal creates and occupies, it is charged with a radical potential. I do not use 'radical' in a traditional political sense but radical as a feeling of being on the very cusp of a change, the edge of a shift. I understand the liminal with regards to micro performance as a radically charged space with a sense of possibilities. This understanding of the radical is also the starting point for a shift in the audience's role and I want to suggest offers a springboard from which we can start to understand and unfold the ways in which a liminoid invitation is made possible.

Victor Turner suggests that the term liminoid refers to experiences that happen within liminal space but instead of being phenomena connected to social or religious ritual, it happens within the circumstances of play. The liminoid is forged out of 'play' scenarios that sit outside of societal rituals or practices and are therefore entered into as 'optional'. It is this optionality in analogous contexts that forges the conditions of the liminoid and ultimately, as I will go on to demonstrate, liminoid acts. I want to suggest that those liminoid invitations are an invitation to play; an attempt to engage the particiapnts in the act of making performance, performing and witnessingsimultaneously. I will suggest that a liminoid invitation engages the participating individuals in 'shallow play'. Turner suggests that play is a

Liminoid mode, essentially interstitial, betwixt-and-between all standard taxonomic nodes [...]. Play is neither ritual action or meditation, nor is it merely vegetative, nor is it just 'having fun'; it also has a good deal of ergotropic and agonistic aggressivity in its odd-jobbing, bricolage style.

(Turner 1986: 31) 
I want to suggest that the offer to play is the offer to commit liminoid acts. Turner suggests that 'shallow play' is inherently liminoid rather than liminal. Lori Shyba supports Turners position and suggests that '[p]eople play with elements of the familiar and defamiliarize them, thereby giving rise to anomalous novelties of collected liminoid phenomena that, among other things, generate chance social engagement' (Shyba 2007:2). The 'ludic' structure of micro-performance dramaturgies invites the participants to engage in 'shallow play' with the performers as equals in the games, tasks and rules. The invitation is to play, but once accepted, it has the potential to become an individualised liminoid act. It would be fair then to suggest that for a liminoid invitation to be offered it must be done so within a liminal space. I would now like to move on and discuss the ways in which You, Hope, Her \& Me sets up a liminal space in order to present a liminoid invitation.

\section{Social schemas \& liminal hybrid space}

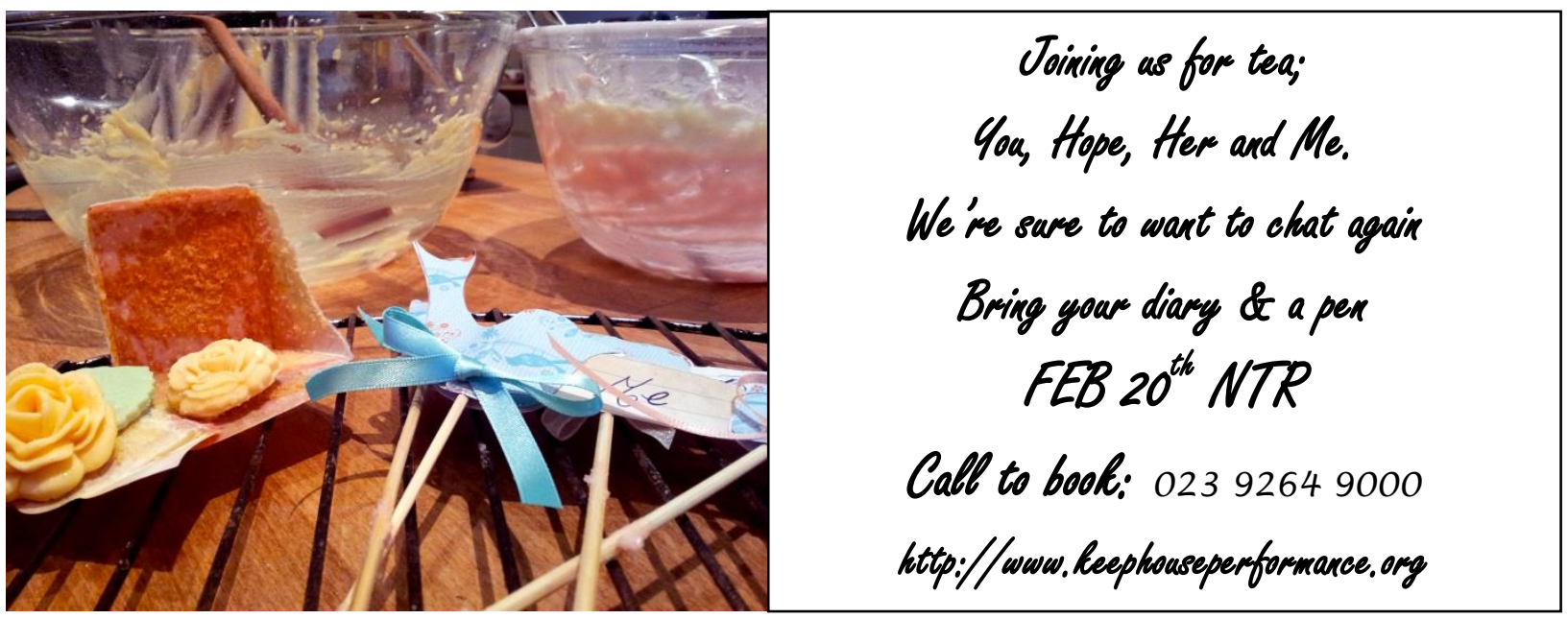

Figure 1: Invitation to the performance that was circulated for the $20^{\text {th }}$ February performance of You, Hope, Her \& Me at the New Theatre Royal.

The liminal space of the performance starts to be constructed before the participants even enter the material space of the live event itself. The invitation sets up and introduces the hybrid nature of the performance space; it marks out the event as performative, due to the venue being a theatre, so 'other' to that of the everyday, but at the same times serves explicitly as an invitation to come for tea. It is the blending of the performative and the social ritual of 'taking tea' that creates the material and conceptual architecture of the liminal performance space. Karen and I were concerned with developing a dramaturgy of performance that created the conditions for the participants to be empowered with the agency to perform their 'hopes' for the future of the NTR. Liminal space provides an architecture that ensures the active agency of the participant and ensures that the role of spectator is eradicated from the dramaturgy. Jaques Rancière also recognises the problematic nature of the traditional role of the spectator in art: '[t]o be a spectator is to be separated from both the capacity to know and the power to act', (Rancière 2009: 2). The invitation draws attention to that hybrid architecture and also indicates the nature of the individuals anticipated shift in role from spectator to participant because of the explicit invitation to 'chat'. Claire Bishop suggests that there are two approaches to participatory art which persistently govern the varied and multiple practices: one approach seems to 
be when the artist creates a participatory situation/event in which to engage the viewer, that makes the work manifest through this engagement. She suggests that this approach to participation in the production of works of art demonstrate that the notion of political commitment is intrinsically linked to the production of participatory art; whether the artist remains visible or disappears into the collective manifestation of the group. In this way, she is suggesting that the intention of participatory art is to question and problematise the usual processes of art production but more so to interrogate and undermine the traditional social and cultural processes that appropriate the reception and consumption of art: '[t]hese three concerns-activation; authorship; community-are the most frequently cited motivations for almost all artistic attempts to encourage participation in art since the 1960's', (Bishop 2006: 12). This blending of the performative and social ritual is then manifest during the live event itself. The event is framed as a performance and so demarcated as such from the everyday by that designation and of course by the venue. Nevertheless, the social dimension of the structure of space is loosely based upon the British social ritual of afternoon tea. We set up a café style environment in the stall bar of the theatre and as such the event relies upon the individual participant recognising the social dimensions of the space and the ritual behaviours that it suggests, as well as the location of that social space within the performative space of the theatre.

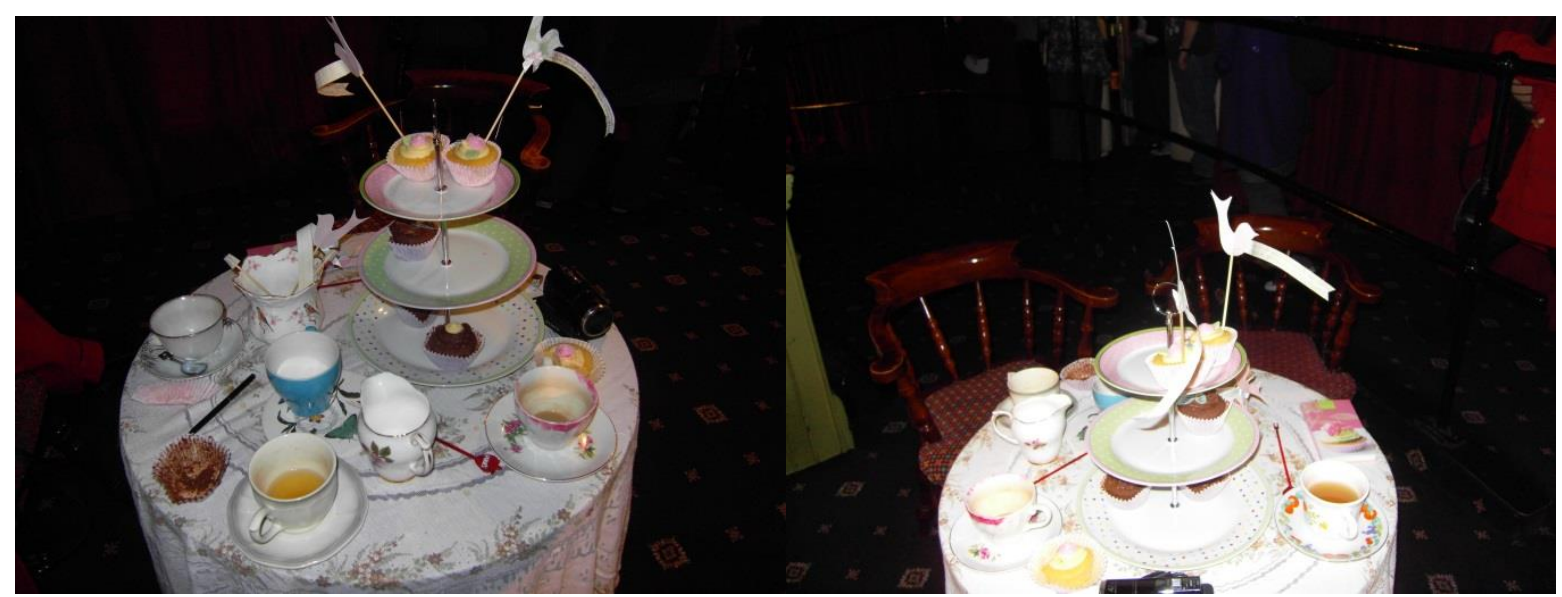

Figure 2 \& Figure 3: The performance space within the stalls bar.

The construction of the performances' hybrid spaces relies on the individual's cognitive architecture, in the form of shared schema to recognise the explicit and implicit facets of the spaces. The use of familiar codes and conventions, albeit fragmented and provisional, relies on the ways, in which the mind/brain receives and processes information, in order to draw attention to that process (and to disrupt it).

The new social hybrid space is reliant upon the process of schema for the participant to recognise the disparate elements that constitute the space but does not allow for a fixed reading or understanding of the hybrid space as a whole. It is familiar enough to be recognised and create a sense of comfort but is disrupted enough by the context of performance to create a liminal space that sits between the two associated architectures at play in the construction of the space. The bricolage of social and performative codes draws attention to the embodied construction of experience and the very nature of how schema marshals our being in the world. The hybrid site assumes that the participants will share enough familiar schemas to recognise those elements, but at the same time refuses to fully bring them into being, disrupting them and creating the opportunity for new practices and 
understandings to be forged between the individuals present. Despite the familiar aspects of the hybrid space, it presents a provisional space that is in constant flux, shifting by and through the participant's engagement with, and in, that particular space. The space relies on the individual participants and performers to produce the space but in such a way as to be conscious of that activity, the constituent parts, as well as the holes, gaps and slippages that the liminality of the space presents. Each individual has to negotiate the material space, marshalled only by their own personal experience and understanding of that space at any given moment. The first time that the participants enter the space they are not given any explicit instructions but they have to make their own decisions about how to 'be' in that space according to their own understanding of the architecture of the space. The material spatial configuration of the event is the first thing that the participants encounter and thus relies on them recognising the culturally specific connotations of the space in order for them to decide how to negotiate their presence in that space. It has to be noted that this initial understanding of the space is constantly problematized and shifted by and through the events that unfold in that space during the duration of the 15-minute encounter.

Green (1996) suggests that the biological level of cognitive architecture describes the nature of brain function and investigates the physiological ways in which we perceive and process sensimori stimuli; in other words, how our bodies register 'being' in the world. The cognitive level describes the affective systems that produce behaviour; the process of assessing the meaning of sensimori stimuli. We can therefore understand sensimori stimuli as the various ways in which the world or that which is 'other' to the body interacts with our material flesh in the world. Schemas are the cognitive process that help the individual to perceive the sensimori stimuli of the space that they encounter and enables them to reach an - albeit provisional understanding of that space and thus intelligent action as a response to that environment:

The content of the cognitive schemas consists of rules, beliefs, and memories that mould the flow of information into cognitive products: interpretation, predictions, and images. The initial cognitive process is generally outside of awareness but the products frequently proceed into awareness.

(Salkovskis 1996: 20-1)

The space of the performance presents certain features that are assumed to be shared and familiar cultural codes. This allows the participant to enter that space and negotiate it according to previous experience and knowledge, although this process is disrupted and problematized by and through their continuing intelligent action within that space:

A schema is a generic concept stored in memory, referring to objects, situations, events, or people. It is a collection of knowledge related to a concept, not a dictionary definition; a schema describes what is usually the case, not necessarily true. 
The participants enter into the hybrid liminal spaces as guests; they enter the space for the first time, they form their opinion and ensuing intelligent action through schema based upon the material stimuli that the space presents. However, the form and structure of the performance were designed to resist a fixed or singular experience or understanding of the space. The participants' initial response to that space, will most likely not be singular or final. The spaces are familiar enough for the elements to be recognisable and for some understanding to be reached through schema. Nevertheless, the form and structure of the performance and the hybridisation of the space between life praxis and performative codes re-configured the spaces in a constant flux in such a way as to render a complete comprehension through schema problematic at best:

To understand the world, a person attempts to 'match' what he [or she] is experiencing to past incidents stored in memory; in other words, he [or she] searches until he [she] has found a schema that summon as or categorises one or more similar stimulus configurations in the past. This 'matching' process requires analogical reasoning, since every stimulus configuration has unique features.

(Larson 1985: 52)

The space of the performance leaves holes, gaps and slippages that cannot be fully understood through existing schema and thus presents the opportunity for new experiences and new schema to be developed. Although Cognitive Science argues that schema is a universal cognitive architectural process of human mind / brains, the very 'stuff' that informs those processes is distinctly subjective and highly personal; ' $[\mathrm{t}] \mathrm{h}$ he attempt to fit on-going experience into a priori patterns may introduce biases and distortion into our understanding of the world. Psychologists use the term assimilation to refer to the adaptation of incoming information to fit preconceived schema' (Larson 1985: 53).

The knowledge and information that the process of schema draws on is different for each individual. However, the schema that both of these productions rely on are cultural: a shared knowledge of certain codes and conventions. There are certain aspects of the space that the performances rely on as widely recognised codes that the majority of the participants will have access to through culturally specific schema. However, after the initial interaction with the space, the performance works to generate the possibility for individuals to commit acts that defy existing schema. The recognisable aspects of the space assume certain shared previous experiences and knowledge that can be accessed through schema; 'cultural schemas are built up through many encounters with similar events or information in one's own culture. Once a cultural schema is developed, information tends to be processed through this schema' (Gudykunst 2005: 410). When the participants enter the space and chose to remain there, they become responsible for producing the social space of the event itself. Whether they choose to play with the performers or watch, drink, eat and chat, they take up a position that is responsible for bringing the social event into being. I want to suggest that this hybrid liminal space was essential for creating the conditions under which the participants could engage in shallow play and feel comfortable with sharing and performing their 'hopes' with us. As Turner explains: 
The distinction between 'subjective' and 'objective' may itself be partly an artefact of the sundering of work and pay. For 'work' is held to be the realm of the rational adaption of means to ends, of 'objectivity', while 'play' is thought of as divorced from this essentially 'objective' realm, and, in so far as it is inverse, it is 'subjective', free from external constraints, where any and every combination of variable can be 'played' with.

(Turner 1982: 34)

To play is to imagine, to confess, to try out, to pretend, but ultimately to create. The invitation to play is an invitation for the individual participant to take responsibility for the devising and performance of the performance itself. It must be noted that, although the conditions for liminoid play or liminoid acts are highly specific, I do not wish to make the 'leisure' versus 'work' distinction of Western culture, because I am no longer convinced by this dichotomy. However, Turner precisely articulates these conditions:

'Leisure', then, presupposes 'work': it is non-work, even an anti-work phase in the life of a person who also works. If we are to indulge in terminological neophily, we might call it anergic as against ergic. Leisure arises, says Dumazedier, under two conditions. First, society ceases to govern its activities by means of common ritual obligations: some activities, including work and leisure, become, at least in theory, subject to individual choice. Secondly, work by which a person earns his or her living is 'set apart from his other activities: its limits are no longer "natural" but arbitrary-indeed, it is organised in so definite a fashion that it can be easily separated, both in theory and in practice, from his free time'. It is only in the social life of industrial civilisations that we find these necessary conditions.

(Turner 1982: 36)

The hybrid space of You, Hope, Her \& Me, is an open space; with enough familiar elements for the guests to gain a provisional understanding of the nature of the space and how to negotiate it but also a space that leaves enough gaps, holes and slippages so that the participants have to engage creatively with the construction of the space as a social sphere. The guests do not simply 'complete' the space, they have to keep re-imagining and re-negotiating the space and their relationship to it through their own interaction with the space, the other guests and the activities that the structure and form present. Rancière acknowledges the slippage of this hybridised space as a re-framing, 'of the relation between bodies, the world they live in and the way in which they are "equipped" to adapt to it. It is a multiplicity of folds and gaps in common experience that change the cartography of the perceptible, the thinkable and the feasible', (Rancière 2009: 72) The participants may enter the space as guests but I want to suggest that they are invited to commit liminoid acts as a communal event that have the potential to transform the role of the guest into the role of the 'material creatorly participant'. 


\section{Anyone for Tea \& Cake?}

Karen and I employed two main task-based elements of dramaturgy to engage the participants in shallow play with the intention of documenting, reflecting and performing their 'hopes': 'hope birds' and diaries.

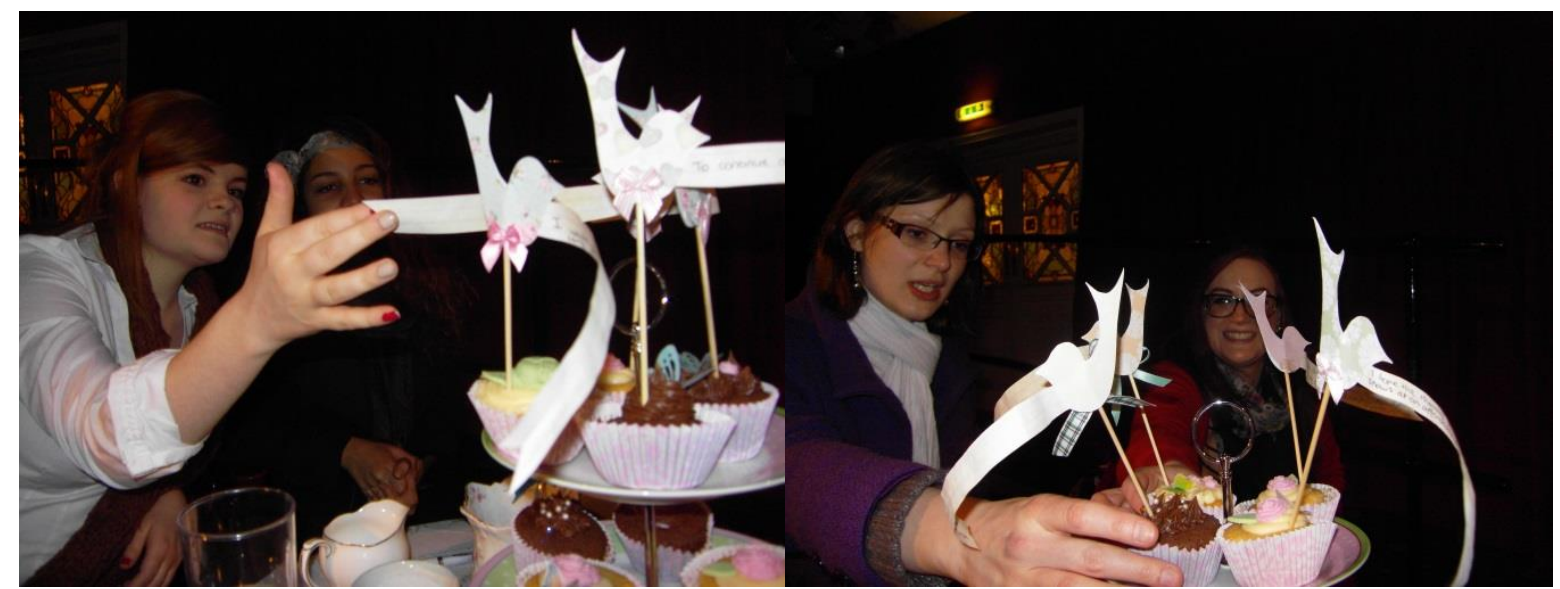

Figure 3 \& Fig. 4: 'Hope Birds'

The 'hope birds' were a device employed as a stimulus to engage the participants in the performance, documentation and sharing of their hopes for the future of the NTR.

Her: this is her (Me gesticulates towards Her) Me: this is me (Her gesticulates towards $\mathrm{Me}$ )

Both: would you like a cup of tea?

Once we welcomed the participants into the hybrid liminal space of the encounter, they were offered a seat and some tea (always green for Her and black for Me). Once we had engaged the participants in a 'chat' about the theatre in general and shared our own hopes, the participants were asked to choose a 'hope bird' and to record their own hope for the future of the NTR. They could then choose a cupcake to plant their 'hope bird' into. Once the participants had planted their own hope into a cupcake, they were offered a cake to eat that already had the hope of another participant planted into it. We asked them to share the hope that they had planted in their cake before consuming the cake. The final aspect of the 'hope bird' structure was to plant the hope of another into a larger cake that represented the theatre itself. 


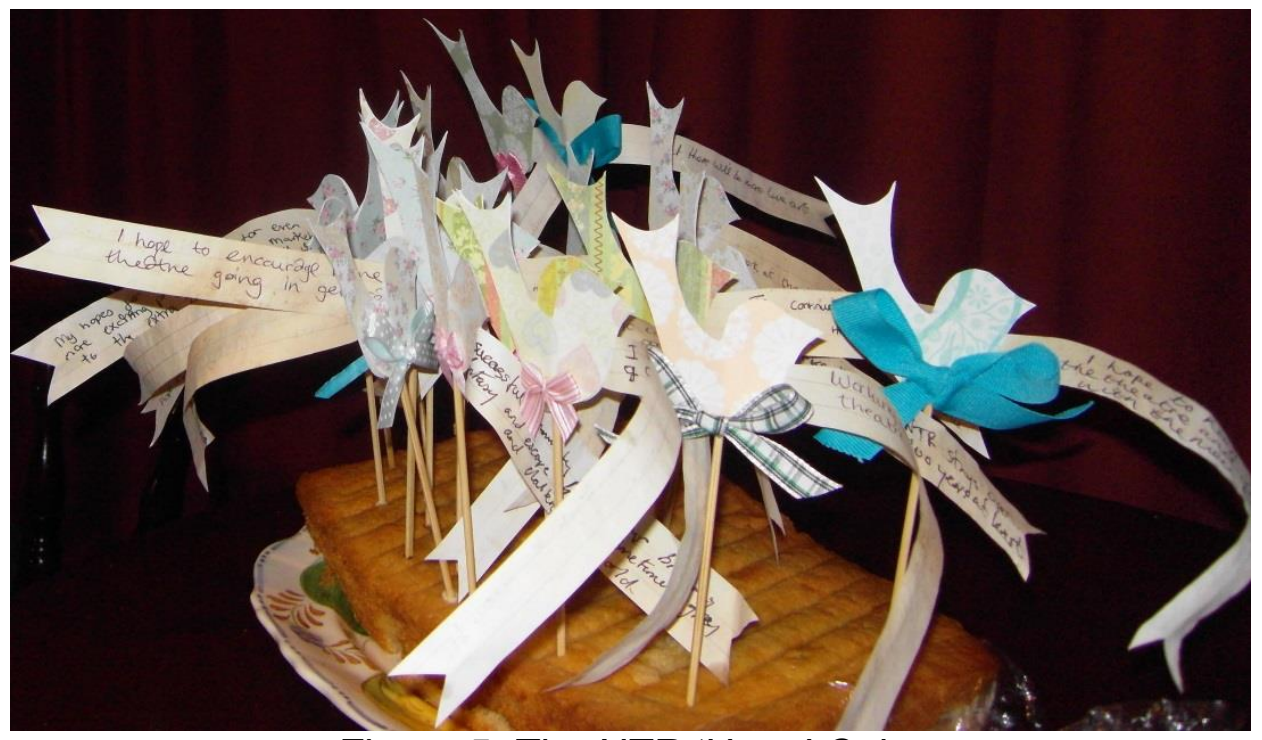

Figure 5: The NTR 'Hope’ Cake

The invitation to 'chat' about their relationship with the theatre and their hopes for its future, engages the individuals in an act that should have been familiar; chatting over tea and cakes is often a ritual associated with 'sharing'. Although each individual will have different experience and knowledge foundations that the schema will draw upon:

Schema remain relatively stable because, once formed, a schema acts like a pair of tinted glasses. For example, the person who believes that people are completely unstable and unreliable sources of support and connection is likely to have an orientating mode that 'sniffs out' any hint of abandonment.

(Fall, Holden et al. 2004: 307)

In employing this kind of informal social ritual, we were assuming certain shared cultural schema. Although the scenario of drinking tea and eating cake might have been a familiar one that provided a recognisable structure, the hybrid liminality of the performance space disrupted that ritual enough to generate the conditions for shallow play; '[i]n this space attributes of objective reality are combined with attributes of imagination leading to the creation of a transitional reality in which one can experiment with different ways of relating to the external world' (Van Leeuwen and Westwood 2008: 154). Geertz describes such instances of play as 'ludus' or 'Iudic': a situation set outside of the everyday as a leisure or entertainment activity. Although the performance employs everyday life praxis, it is due to the performative context that the event is highlighted as something separate from the everyday. The participants can experiment and reflect upon their relationship to the theatre, whilst in liminal proximity to the theatre and of course the ritual of sharing itself. This suspension of cultural and societal norms generates the possibility for new insights and understandings to be forged but without serious consequence in life praxis for the individual. 'Shallow play' situations give permission for its participants to imagine and create alternatives and possibilities outside of the accepted cultural/societal norms. The invitation to share a 'hope' via a 'hope bird' is a liminoid one. The 'hope bird' is essentially an invitation to the individual to commit an act. The participants, Karen and I all work together to play, imagine and create through the act of sharing 
our own hopes both through discussion and via the 'hope birds'. The 'hope birds' not only present an invitation but they also document the performance of the participants at the same moment as being the performance itself. In this way they might be understood to function in two ways: first, as performative documentation - for they are produced in the event and then beyond this - and second, as a performative reenactment - as they become an artefact of the performance. I will unpack this in more depth at a later stage in the article.

\section{Bring Your Diary \& a Pen; we're sure to want to chat again!}

The second major device that we employed to create a liminoid invitation was the booking of a future appointment. While each of the participants enjoyed their chosen cupcake, Karen and I discussed the importance of dates in relation to the significant dates for the development of the NTR (the day of the first set of encounter being the date that marked the start of the development of the project). We both discussed the role of our diaries in our lives and our own involvement with the future of the NTR. We then asked the participants to tell us about their own diaries and their significance to them. We drew the encounter to a close by asking the participants to book a meeting with us for the following year on the same date, in the newly developed NTR - whatever form it might have at that point. This task was designed to engage each participant in an imagining of the future NTR in relation to their own hopes; a liminoid invitation to create, to imagine and to propose possible futures. The device of a liminoid invitation such as this is not imagined in the way that Happenings privileged new primary experience, but as consciously playful and reflexive construction of possible futures. The liminoid invitation to play with the notions of possible futures is the performance device employed to generate those potentialities, but, in doing so, also documents them.

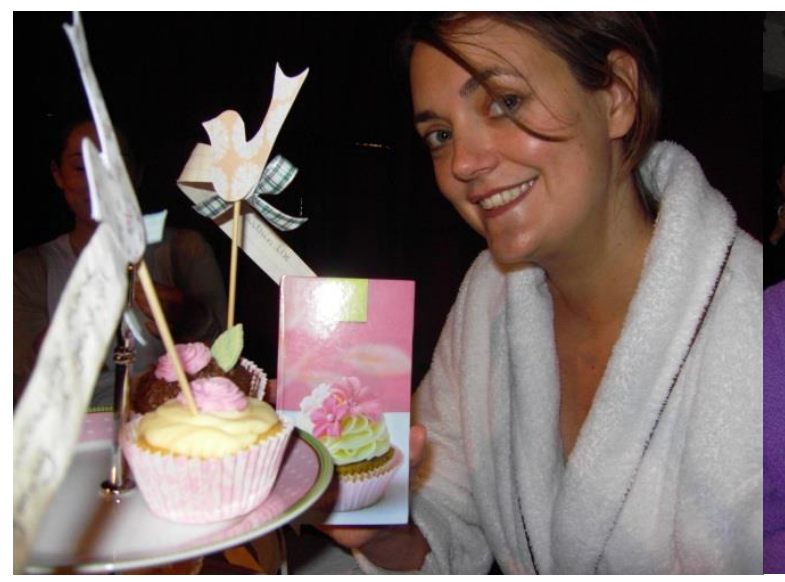

Figure 6: Karen and her diary

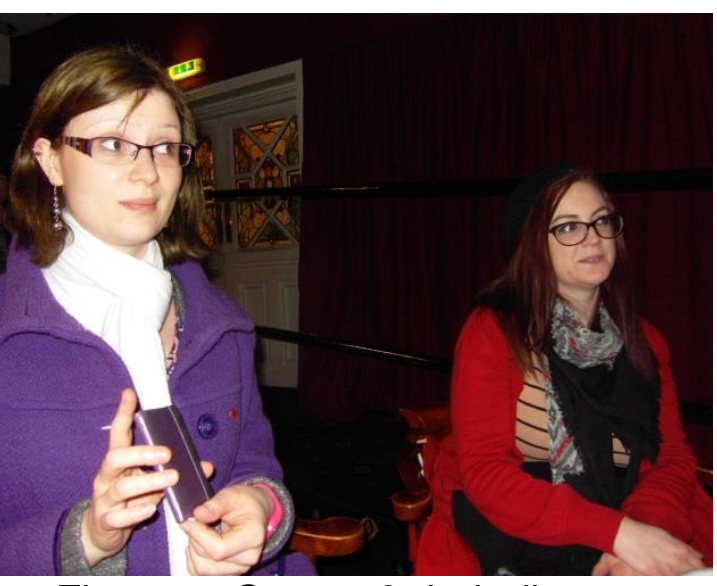

Figure 7: Guests \& their diary

The 'rules of engagement', such as the 'hope birds' and the booking of a future meeting, form the structure of the work, but these become manifest as a series of individual acts through the undertaking of tasks themselves. The games and tasks are what constitute the form and thereby the ensuing acts that generate the actual performance itself. The rules and activities were indeed predetermined by the makers, Karen and I, but the ways in which they materially took form was entirely provisional on the participant's interaction. We may have decided what it is we 
wanted to play with, but each participant decided how that came into being. The tasks and rules created the dynamic of the performances. They provided the performance material which influenced the pace, tension and dynamics and which where particular to each and every performance. The form of these encounters is a pregnant scenario, but in order to become borne, it requires the participant to accept the invitation to play and to commit liminoid acts.

\section{Liminoid Acts}

The liminoid acts that the various tasks produce shape and bring into being the performance event itself. Each participant's bringing into being of the performance in collaboration with the performers is an act in real time; it is a material act. Their participation materially affects the other participants, including the performers' experience of the encounter. When the participants take up the invitation to play, they take up the creative responsibility for the performance in a material way. Accepting the invitation to play is accepting creative responsibility. When the participants offer a hope, sharing their notions of a future NTR, they are engaged in 'shallow play', each imagining a possible future or the sharing an anecdote presents a liminoid act. Upon entering the hybrid space of the encounter, the participants become inextricably bound up as part of the event itself in very much the same way as a guest at a party makes up that occasion. Once the participants have entered into the hybrid space of the encounter, they assume the role of 'material participant' and become partly responsible for how that event comes into being. Before the participants have entered into any creative acts or activities, they become a material factor of the environment that constitutes and performs the social space. They materially impact upon the space and others experience of that space without committing any action other than negotiating that space. The 'material participant' is distinct as a role from Bennett's 'co-creator' in two ways: firstly, the 'co-creator' is usually separate from the material performance: unlike the 'material participant' who is a part of the performance itself and cannot be separated from it, the 'co-creator' is positioned as a spectator, albeit an active one. Secondly, the 'co-creator' that is often produced by postdramatic and postmodernist performance is engaged in an intellectual and conceptual manner to participate in the coding and decoding of signification, and does not have any agency over the material event in any meaningful way. The 'material participant' is a part of the performance; they have to negotiate the liminal hybrid space and materially position themselves within that space, thereby impacting and acting upon their own and others' coding and decoding of that space in actual rather than conceptual ways. Their participation is an act, but not always a liminoid one; their material presence alone impacts and acts upon the performance. Once a liminoid invitation has been accepted and a liminoid act is engaged in, the participant becomes a material creatorly participant.

When an individual participant accepts the invitation to play, joining in a task or activity, they take up the potential for committing a liminoid act and assert their own agency within the liminoid structured conditions of play. The invitation to play is in this case a personal one; and so, each participant and the performers collaborate in the task of a 'creatorly' endeavour and in doing so potentially commit a liminoid act. When the participant chooses to play with the performers, they accept responsibility for the production of the performance, which is a creative responsibility. In playing with the other participants and performers, they engage in a creatorly process that 
constitutes the performance itself, but also affects all of the other participants' experiences of that performance. The material creatorly participant is responsible for generating the actual performance, they engage, to all intents and purpose, in devising and performing through the process of play. In doing so, they potentially generate new discoveries and insights through reflection of primary experience. The play generates a new primary experience for each participant but the performative context creates a reflective frame that de-doxifies those primary experiences as constructed. Hutcheon argues that postmodernism de-doxifies our cultural practices and representations, it unravels and exposes the underlying knowledge and power structures as constructed rather than naturalised processes;

To adapt Barthes general notion of the 'doxa' as public opinion or the 'voice of nature' and consensus, postmodernism works to 'de-doxify' our cultural representations and their undeniable political import.

(Hutcheon 1989: 189)

Whether the participants accept the invitation to play or not, they are fundamentally implicated in the fabric of the performance in a material way and this itself represents the nature of agency that is ontologically embedded into a liminoid invitation.

\section{Performing and re-enacting the NTR's heritage and legacy.}

This dynamic of creatorly agency in the role of the participants at these encounters are the conditions that we employed in order to find ways to perform, document and reflect upon the community's engagement and hopes for the future of the theatre. The dramaturgical nature of a liminoid invitation and the active agency of the role that such an invitation generates for its participants, created the conditions under which, Karen and I could utilise the liminoid acts as a mode of performative documentation and re-enactment. Our PAR objectives were to find performative devices that would enable us to record, document and reflect upon the community's hopes for the future of the NTR project. The liminoid nature of micro-performance dramaturgy enabled us to achieve those research aims. The various liminoid invitations create the performative opportunities for it is the liminoid acts that perform the heritage and legacy of the theatres community by engaging individuals in play. Through committing such acts, the participants perform, record, document and reflect upon their existing relationship with the theatre and their hopes for its future. Through engaging in 'shallow play' that explores their own past and current relationship with the theatre, they perform the localized and personal heritage of the theatre. By committing liminoid acts that explore their hopes and ideas for its possible futures, they are performing and documenting the possible legacy of the theatre.

During the performance we invited the participants to use their phones to take images, to tweet and to share photos in the moment through any social media sites that they might use. Karen and I also engaged in this activity. During the performance we uploaded images directly to our twitter feeds and to Facebook. I want to suggest that the documentation of the liminoid acts during the performance encounter itself serve as digital re-enactments of them. The migration of the liminoid 
acts from live events to digital ones is constructed out of various artifacts (including images of the hope birds), which generate both primary and secondary source material directly as the traces left behind from the performances themselves, but also through supporting research activity. Their documentation intended to capture the participants' perceptual and experiential experiences. I want to suggest that the performative re-enactments of the liminoid acts not only re-present the live performances but also map the migration of practice to dissemination in a performative manner. Each 'hope bird' generated from the encounters will be posted to the website that accompanies this on-going project (http://www.keephouseperformance.org/\#! current-projects). The website provides a comments box available for the duration of the NTR's build project so that it can continue to re-enact its original liminoid acts as a continued digitalized version of the performance, but also serve as a living archive of the legacy and heritage of the NTR. The project will continue into 2014 with more encounters. After the completion of the building project and the 2014 meetings with the encounter participants, the documentation of all aspects of this project will be crafted into a quilted artefact that will be donated back to the NTR for display in the refurbished building; a material mapping of the 'hopes' of the theatre's community.

\section{References}

Bennett, S. (1990). Theatre audiences: a theory of production and reception. London: Routledge.

Bishop, C. (2006). Participation. London: Whitechapel.

Broadhurst, S. (1999). Liminal acts: a critical overview of contemporary performance and theory. London: Cassell.

Fall, K. A., J. Holden, et al. (2004). Theoretical models of counselling and psychotherapy. Philadelphia, Pa.: Hove, Brunner-Routledge.

Green, D. W. (1996). Cognitive science: an introduction. Oxford: Blackwell

Publishers.

Gudykunst, W. B. (2005). Theorizing about intercultural communication. Thousand Oaks, Calif.; London, Sage.

Hutcheon, L. (1989). The politics of postmodernism. London: Routledge.

Kershaw, B. (1999). The radical in performance: between Brecht and Baudrillard. London: Routledge.

Larson, D. W. (1985). Origins of containment: a psychological explanation.

Princeton; Guildford, Princeton University Press.

McConachie, B. A. and F. E. Hart. (2006). Performance and cognition: theatre studies and the cognitive turn. London: Routledge.

Rancière, J. (2009). The emancipated spectator. New York, London: Verso. 
Salkovskis, P. M. (1996). Frontiers of cognitive therapy. New York: London, Guilford Press.

Shyba, Lori. (2007).'Social Critique gets Real: From Games for Change to Change in Game', (Panel Discussion). Proceedings of DiGRA 2007. Tokyo, Japan. September 2007.

Tate. (2013). http://www.tate.org.uk/whats-on/tate-modern-tanks/display/suzannelacy-crystal-quilt, accessed on 12/02/2013.

Turner, V. W. and E. M. Bruner, (Eds). (1986). The anthropology of experience. Urbana: University of Illinois Press.

Turner, V. W. (1982). From Ritual to Theatre: The Human Seriousness of Play. New York: Performing Arts Journal Publications.

Turner, V. W. (1969). The ritual process: structure and anti-structure. London: Routledge \& K. Paul.

Van Leeuwen, L. and D. Westwood (2008). 'Adult play, psychology and design.' Digital Creativity 19(3): 153.

\section{Author Biography}

I am a practitioner and scholar with a commitment to making work that explores the notions of community, space and play. I am interested in exploring and generating liminal spaces that sit between social and arts practices in order to imagine the potential of new relationships/spaces forged through liminoid acts and play. My research interests are: production and reception theory of experimental contemporary performance; specifically immersive, one on one, micro performance \& participative dramaturgies, documentation of performance, augmented reality in performance and digitalised immersive technologies. I am co-artistic director of KeepHouse performance with Dr Karen Savage, (www.keephouseperformance.org).

I am currently a lecturer at the University of Portsmouth in the School of Creative Arts, Film \& Media. 